University of Nebraska - Lincoln

DigitalCommons@University of Nebraska - Lincoln

Robert Katz Publications

Research Papers in Physics and Astronomy

February 1969

\title{
Electron Energy Dissipation
}

E. J. Kobetich

H. H. Wills Physics Laboratory, University of Bristol (England)

Robert Katz

University of Nebraska-Lincoln, rkatz2@unl.edu

Follow this and additional works at: https://digitalcommons.unl.edu/physicskatz

Part of the Physics Commons

Kobetich, E. J. and Katz, Robert, "Electron Energy Dissipation" (1969). Robert Katz Publications. 99.

https://digitalcommons.unl.edu/physicskatz/99

This Article is brought to you for free and open access by the Research Papers in Physics and Astronomy at DigitalCommons@University of Nebraska - Lincoln. It has been accepted for inclusion in Robert Katz Publications by an authorized administrator of DigitalCommons@University of Nebraska - Lincoln. 
Published in Nuclear Instruments and Methods 71 (1969), pp. 226-230. Copyright (C North-Holland Publishing Co. (Elsevier). http://www.sciencedirect.com/science/journal/01689002 Used by permission.

Supported by the U.S. Atomic Energy Commission and the National Science Foundation

Submitted February 20, 1969

LetTer to THE Editor

\title{
Electron Energy Dissipation
}

\author{
E. J. Kobetich* and R. Katz \\ Behlen Laboratory of Physics, University of Nebraska-Lincoln, Lincoln, Nebraska 68508, U.S.A. \\ * Present address: H. H. Wills Physics Laboratory, University of Bristol (England).
}

\begin{abstract}
A new algorithm for the computation of the energy dissipated by normally incident, monoenergetic electron beams, provides good agreement with experimental data and with the computations of Spencer.
\end{abstract}

For the interpretation of many radiation effects, a simple computing algorithm which yields information electron beams is of great utility. Such an algorithm ${ }^{1}$ about the dissipation of the energy of normally incident has been profitably applied to the study of heavy ion interactions, through a model which attributes heavy ion

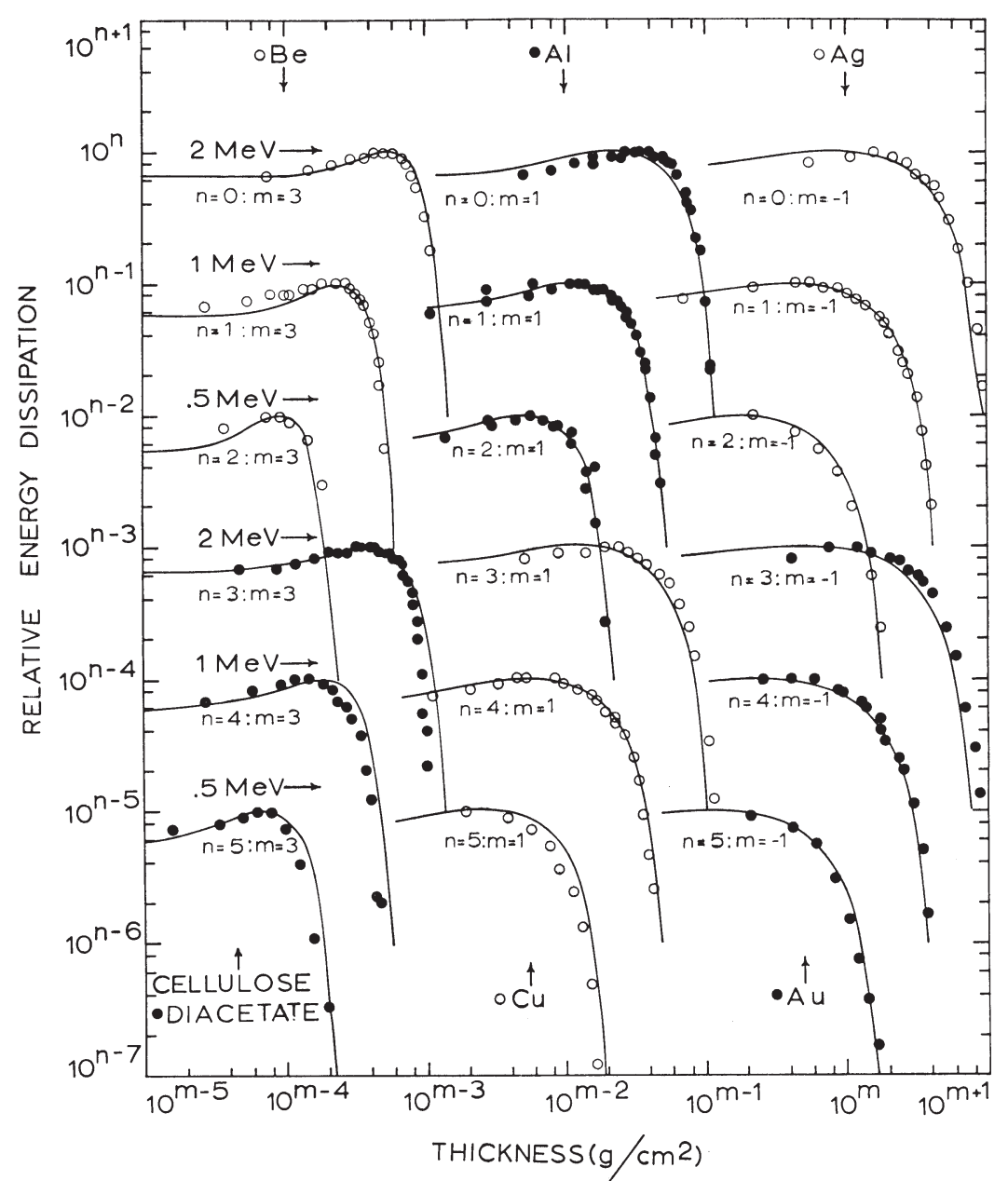

Figure 1. Relative electron energy dissipation data from Aiginger et al. ${ }^{5}$ for $0.5,1.0$, and $2 \mathrm{MeV}$ electrons in Be, cellulose diacetate, $\mathrm{Al}, \mathrm{Cu}, \mathrm{Ag}$, and $\mathrm{Au}$, plotted over calculations from equation (4). Since these data are in relative units, with the maximum dissipation set to unity in each case, the calculations have been similarly normalized. 


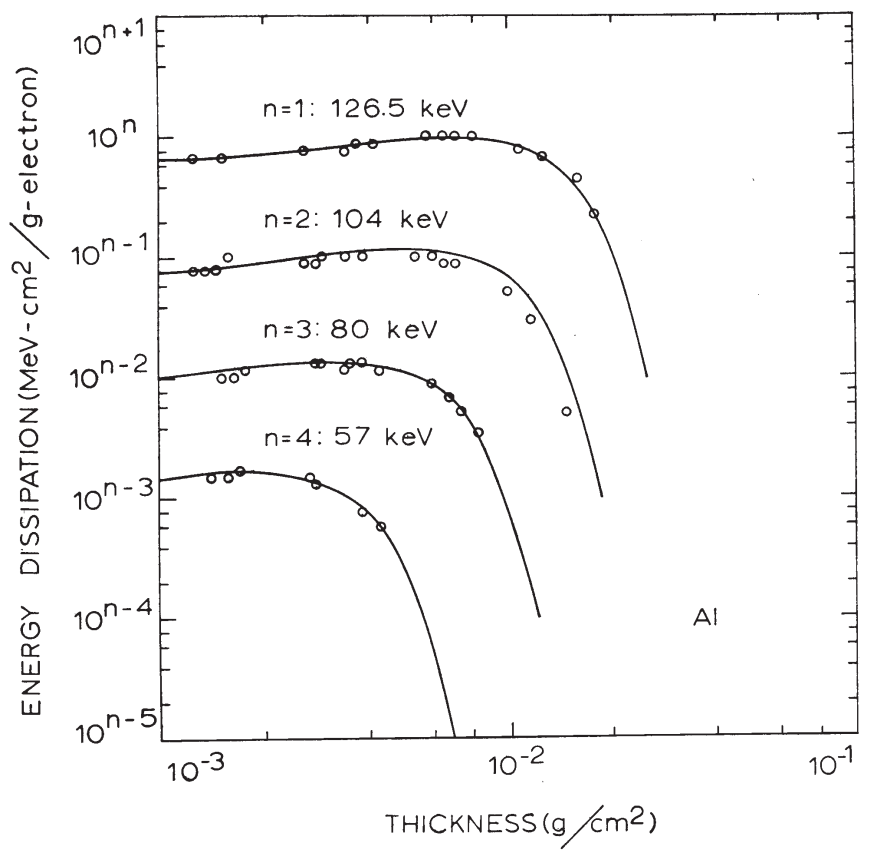

effects to the dose of ionization energy deposited by $\delta$ rays. The present paper describes an improved form of the earlier algorithm, developed for the same purpose.

\section{The characteristic thickness:}

The work of Depouy et al. ${ }^{2}$ has shown that the definition of the practical (extrapolated) range of electrons in many materials is somewhat ambiguous, and that a more suitable description of the interaction of electron beams with foils is obtained through use of the characteristic thickness $r_{\eta}$, at which the probability for electron transmission is $\eta$. These authors have given expressions for the transmission probability (for an energy interval $50-1,200 \mathrm{keV}$ ) and its associated characteristic thickness (for an energy interval $20 \mathrm{keV}$ to $20 \mathrm{MeV}$ ) as a function of the atomic number and atomic mass of the absorber.

Figure 2. Electron dissipation data from Huffman et al. ${ }^{6}$ for 57 , 80, 104, and $126.5 \mathrm{keV}$ electrons in $\mathrm{Al}$, plotted over calculations from equation (4).

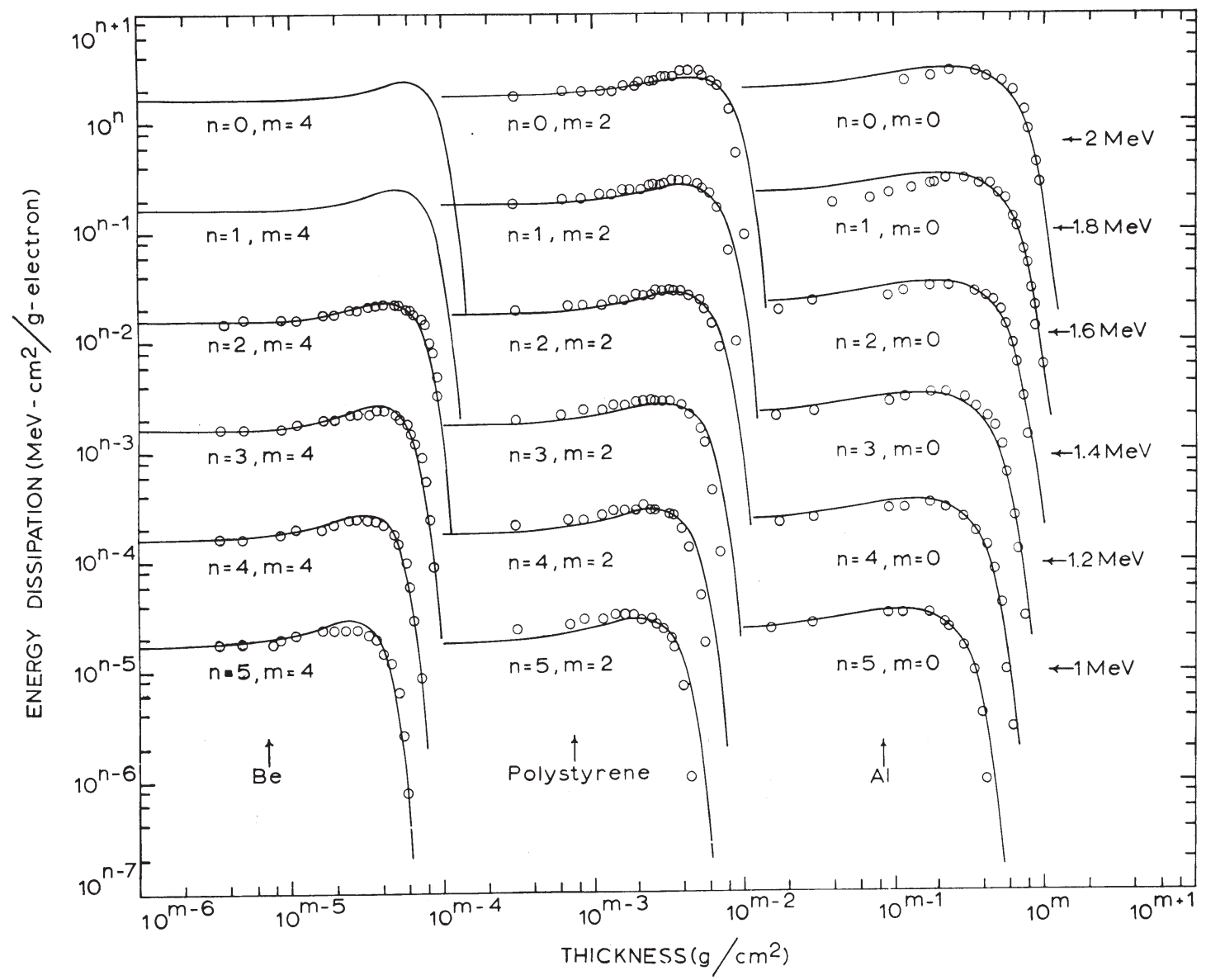

Figure 3. Electron energy dissipation data from Nakai et al. ${ }^{7}$ for 1.0, 1.2, 1.4, 1.6, 1.8, and 2.0 MeV electrons in Be, polystyrene, and $\mathrm{Al}$, plotted over calculations from equation (4). 


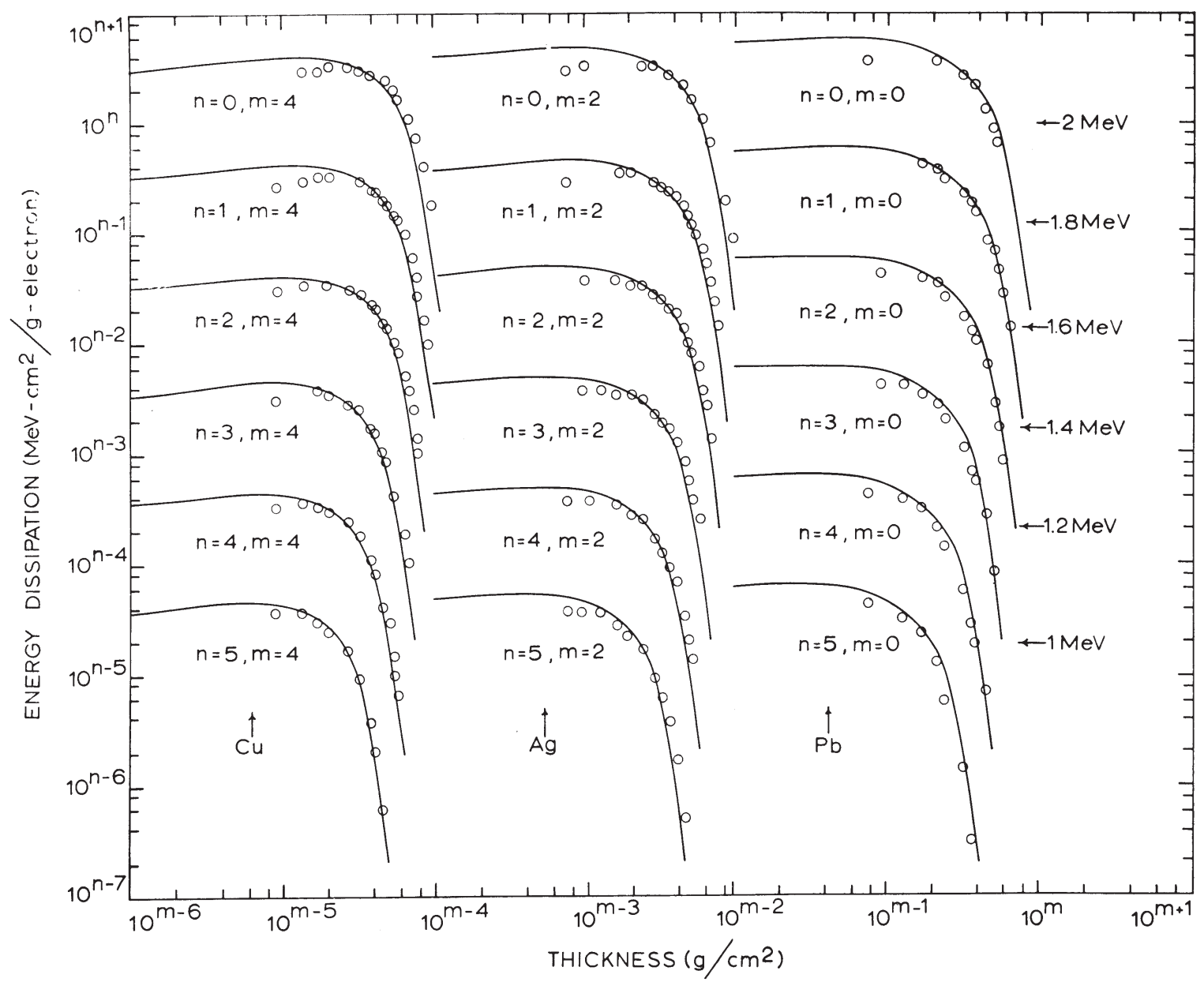

Figure 4. Electron energy dissipation data from Nakai ${ }^{7}$ for 1.0, 1.2, 1.4, 1.6, 1.8, and $2.0 \mathrm{MeV}$ electrons in $\mathrm{Cu}$, $\mathrm{Ag}$, and $\mathrm{Pb}$, plotted over calculations from equation (4).

Since the form of the expression given by Depouy et al. for the characteristic thickness does not lend itself either to application to gases, or to extrapolation to lower energies, constants have been calculated for a formula of Weber, ${ }^{3}$ giving the $5 \%$ characteristic thickness, $r_{0.05}$, for electrons of incident energy $w$, for use as a starting place in the development of an energy dissipation algorithm.

The expression

$$
r_{0.05}=A w[1-B /(1+C w)],
$$

where

$$
\begin{aligned}
& A=\left(1.06 Z^{-0.38}+0.18\right) \times 10^{-3} \mathrm{~g} / \mathrm{cm}^{2} \cdot \mathrm{keV}, \\
& B=0.22 Z^{-0.055}+0.79, \\
& C=\left(1.3 Z^{0.3}+0.21\right) \times 10^{-3} / \mathrm{keV},
\end{aligned}
$$

yields results in 5\% agreement with those of Depouy et al., for the materials investigated by these authors.

Our earlier algorithm for the computation of electron energy dissipation made use of a practical range-energy relation for aluminum, based on the formula of Weber, ${ }^{3}$ in combination with an expression for the probability for the transmission of electrons through any material, due to Rao. ${ }^{4}$

The present work utilizes the expressions of Depouy et al. for the transmission probability $\eta$ and the characteristic thickness $r$ as its starting place, recasting the latter expression in the form of equation (1). Constants and exponents in these expressions have been altered through a parameter-seeking computer program, set to minimize the difference between computations from the algorithm and experimental energy dissipation data. The procedure used allows Z-dependence in both $r$ and $\eta$.

\section{Energy dissipation algorithm:}

The structure of the energy dissipation algorithm is motivated by the argument that electrons of initial energy $w$ and characteristic thickness $r$ which penetrate a foil of 


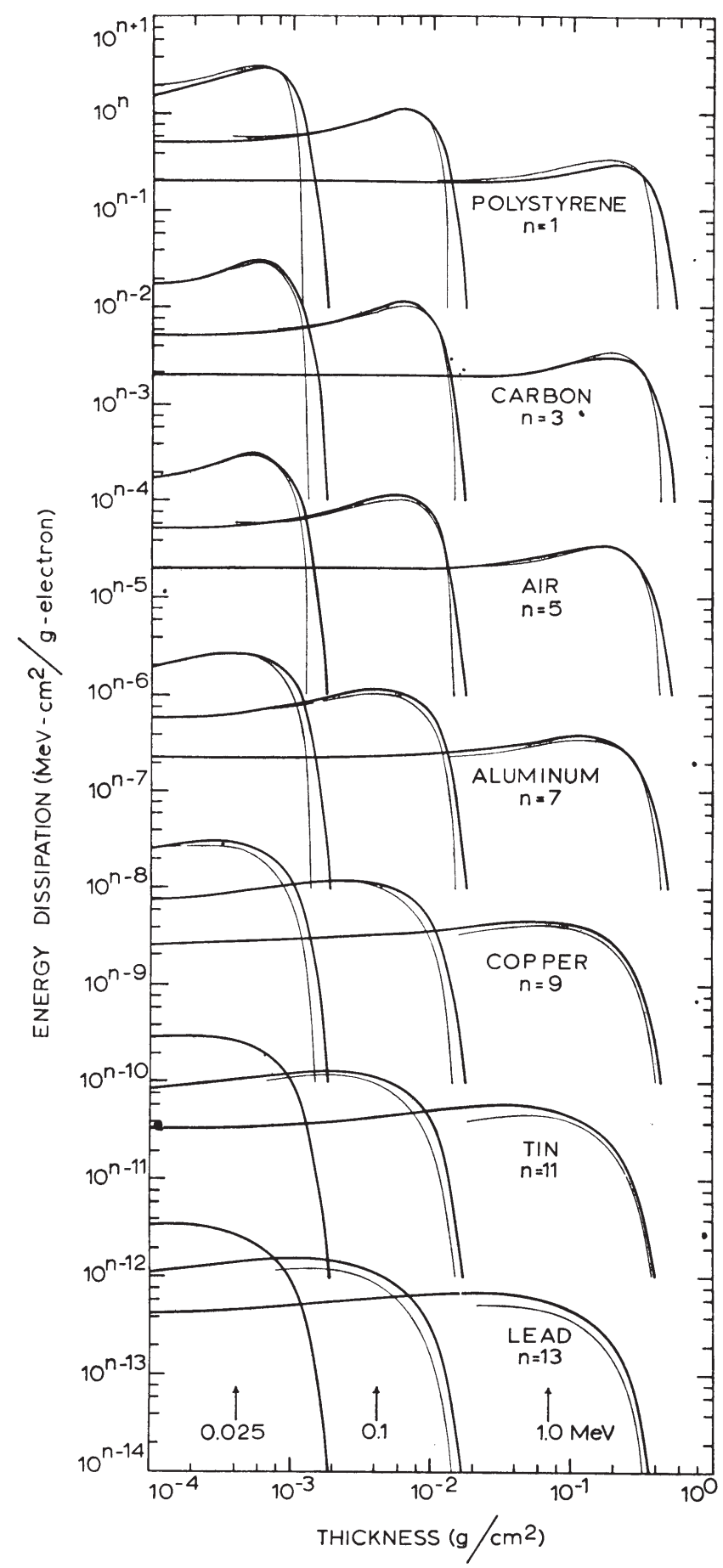

Figure 5. Electron energy dissipation for $0.025,0.1$, and $1 \mathrm{MeV}$ electrons in polystyrene, $\mathrm{C}$, air, $\mathrm{Al}, \mathrm{Cu}, \mathrm{Sn}$, and $\mathrm{Pb}$. Light lines are from Spencer, ${ }^{8}$ while dark lines are from equation (4).

thickness $t$ have residual energy $W$, which can be found from the characteristic thickness-energy relationship as the energy to go to the residual distance $r-t$. The residual energy may be written in functional form as

$$
W(r, t)=w(r-t) .
$$

The energy transmitted through a foil by a single incident electron is then approximated by the product of $\eta$, the probability of transmission, and $W$, the residual energy. The energy $E$, dissipated at depth $t$ by a beam containing one electron $/ \mathrm{cm}^{2}$ may be represented as

$$
E=\mathrm{d}(\eta W) \mathrm{d} t .
$$

The use of a characteristic thickness-energy relationship in such a structure suffers from several difficulties. First, it appears to neglect back-scattering, though it may be argued that the energy lost from a layer $\mathrm{d} t$ by backscattering is compensated by energy back-scattered from later layers. Second, all electrons are represented by an underscattered class, namely those which penetrate to the characteristic distance. Third, the energy deposited by the least scattered electrons, which penetrate to a thickness $t>r$, is neglected. It must therefore be expected that improved agreement with experiment will arise from limiting the applicability of equation (3) to some thickness less than $r_{0.05}$, and by utilizing a second expression expressly created to accomodate straggling beyond that thickness. This has been done, with the following results.

The energy density $E(t)$, dissipated in a material of atomic number $Z$, in a layer of thickness $\mathrm{d} t$ at depth $t$ by a normally incident beam containing 1 electron $/ \mathrm{cm}^{2}$, of initial energy $w$, whose characteristic thickness is $r$, is given by the expressions:

for $t / r \leq 0.9$ :

$$
\begin{array}{ll}
E(t) & =\mathrm{d}(\eta W) / \mathrm{d} t \\
\eta & =\exp \left\{-(q t / r)^{p}\right\} \\
W(r, t) & =w(r-t) \\
r & =A w[1-B /(1+C w)] \\
q & =0.0059 Z^{0.98}+1.1 \\
p & =1.8\left(\log _{10} Z\right)^{-1}+0.31 \\
A & =\left(1.06 Z^{-0.38}+0.18\right) \times 10^{-3} \mathrm{~g} / \mathrm{cm}^{2} \cdot \mathrm{keV}, \\
B & =0.21 Z^{-0.055}+0.78 \\
C & =\left(1.1 Z^{0.29}+0.21\right) \times 10^{-3} / \mathrm{keV}
\end{array}
$$

for $t / r>0.9$ :

$$
=E(0.9 r) \times\{\eta / \eta(0.9 r)\}^{4 / p} .
$$

For mixed materials and compounds, $\mathrm{Z}$ is replaced by its average value, weighted over the mass fractions.

\section{Comparison with experimental data:}

The precise expressions for the constants $q, p, A, B$, and $C$, in equation (4) depends on the data which is represented by these expressions, for there is some disagreement among investigators. The values reported were obtained by a criterion of best agreement with the combined data of Aiginger et al., ${ }^{5}$ Huffman et al., ${ }^{6}$ and Na- 
kai et al. ${ }^{7}$ Calculations from equation (4) are compared with their experimental results in Figures 1-4. For completeness we also show the comparison of calculations from equation (4) with the theory of Spencer ${ }^{8}$ in Figure 5 . The results of the present computing algorithm represent a significant improvement over our earlier effort. Over a wide range of materials and energies, equation (4) represents experimental data to an average deviation of about $10 \%$, which approximates the uncertainty of the data itself.

We thank R.-A. Nelson for her assistance in the preparation of the manuscript, and C. A. Crane for supplying us with his program "MINIFUN."

\section{References}

1) E. J. Kobetich and R. Katz. Phys. Rev. 170 (1968) 391.

2) G. Depouy, F. Perrier, P. Verdier, and F. Arnal, Compt. Rend. Acad. Sci. (Paris) 258 (1964) 3655; 260 (1965) 6055.

3) K. H. Weber, Nucl. Instr. and Meth. 25 (1964) 261.

4) B. N. Subba Rao, Nucl. Instr. and Meth. 44 (1966) 155.

5) H. von Aiginger and H. Hubeny, Atomkernenergie 10-89 (1965) 479; H. von Aiginger and E. Gonauser, Atomkernenergie 13-8 (1968) 33.

6) F. N. Huffman, J. S. Cheka, B. G. Saunders, R. H. Ritchie, and R. D. Birkhoff, Phys. Rev. 106 (1957) 435.

7) Y. Nakai, Japan J. Appl. Phys. 2 (1963) 743; Y. Nakai, K. Matsuda, T. Takagaki, and K. Kimura, Nippon Hoshasen Kobunshi Kenkyu Kyokai Nempo 6 (1964/65) 7.

8) L. V. Spencer, Nat. Bur. Std. (U. S.) Monograph 1 (1959). 